\title{
CONTROLE ESTRATÉGICO DE Amblyomma cajennense (FABRICIUS, 1787) (ACARI: IXODIDAE) EM EQÜINOS, MINAS GERAIS, BRASIL - PARTE I*
}

\author{
ARILDO P. DA CUNHA ${ }^{1}$; ANA CRISTINA P. DE PAIVA BELLO ${ }^{1}$; ROMÁRIO C. LEITE ${ }^{2}$; EDUARDO BASTIANETTO ${ }^{1}$; \\ ANTÔNIO CÂNDIDO C. LEITE RIBEIRO3; CAROLINA MARIA V. DE FREITAS ${ }^{4}$; PAULO R. OLIVEIRA ${ }^{2}$
}

\begin{abstract}
CUNHA, A.P. DA; BELLO, A.C.P. DE P.; LEITE, R.C. BASTIANETTO, E.; RIBEIRO, A.C.C.L.; FREITAS, C.M.V. DE; OLIVEIRA P.R. [Strategic control of Amblyomma cajennense (Fabricius, 1787) (Acari: Ixodidae) on horses, Minas Gerais, Brazil - Part I.] Controle estratégico de Amblyomma cajennense (Fabricius, 1787) (Acari: Ixodidae) em eqüinos, Minas Gerais, Brasil - Parte I. Revista Brasileira de Parasitologia Veterinária, v. 16, n. 4, p. 221-228, 2007. Escola de Veterinária, Departamento de Medicina Veterinária Preventiva (DMVP), Universidade Federal de Minas Gerais (UFMG), Av. Antônio Carlos, 6627, São Francisco, Belo Horizonte, MG 31270-010, Brasil. E-mail: rcleite@vet.ufmg.br

The aim of this study was to verify the efficiency of a strategic control program of Amblyomma cajennense in horses under field conditions. Acaricide treatments were applied at seven days intervals and divided in two series, the first one beginning in April 2004 (eight treatments), and the second one beginning in July 2004 (five treatments), aiming to control larvae and nymphs of the tick. A pyrethroid chemical base cypermethrin 0.015\% was used for spraying the horses. There was a reduction of $44.85 \%$ in the adults infestetion of the tick in the period of October 2004 to March 2005, and 59.74\%, in February and March 2005. Results showed the effectiveness of the strategic control. Important administrative and operational procedures can interfere with the practical application of this technology, and should be considered.
\end{abstract}

KEY WORDS: Amblyomma cajennense, strategic control, equines.

\section{RESUMO}

Objetivou-se verificar a eficiência de um programa de controle estratégico de Amblyomma cajennense em eqüinos sob condições de campo. Os tratamentos carrapaticidas foram realizados a cada sete dias e divididos em dois módulos: o primeiro com início em abril e término em maio de 2004 (oito banhos) e o segundo com início e término em julho de 2004 (cinco banhos), visando atingir as larvas e ninfas do carrapato. Empregou-se a base química piretróide - cipermetrina 0,015\%, para banhar os eqüinos. Após o programa de controle houve uma redução de 44,85\% da carga parasitária de adultos do carrapato no período de outubro de 2004 a março 2005, e de $59,74 \%$, em fevereiro e março de 2005 . Os resultados

\footnotetext{
* Sob os auspícios do CNPq (Processo 479731/2004-7).

${ }^{1}$ Curso de Pós-Graduação em Ciência Animal, Escola de Veterinária, Universidade Federal de Minas Gerais (UFMG).

${ }^{2}$ Escola de Veterinária, Departamento de Medicina Veterinária Preventiva (DMVP), UFMG, Avenida Antônio Carlos, 6627, São Francisco, Belo Horizonte, MG 31270-010, Brasil. E-mail: rcleite@vet.ufmg.br

${ }^{3}$ EMBRAPA Gado de Leite.

${ }^{4}$ Universidade Presidente Antônio Carlos, UNIPAC.
}

demonstraram a efetividade do controle estratégico. No entanto, consideram-se importantes fatores operacionais e de gerenciamento que podem interferir na aplicação prática desta tecnologia.

PALAVRAS-CHAVE: Amblyomma cajennense, controle estratégico, eqüinos.

\section{INDRODUÇÃO}

Amblyomma cajennense pertence à família Ixodidae, subfamília Amblyomminae e ao gênero Amblyomma, tendo sido primeiramente relatado em Cayenna (Guiana Francesa) e descrito por Fabricius em 1787 (OLIVER, 1989). Sua área de distribuição abrange a América do Sul, América Central, Sul da América do Norte e Caribe (ARAGÃO, 1936). É um carrapato trioxeno, isto é, que utiliza três hospedeiros para a realização do seu ciclo parasitário (ROHR, 1909). Tem como característica uma baixa especificidade parasitária, podendo parasitar várias espécies de animais domésticos e silvestres, embora os eqüídeos sejam os hospedeiros preferenciais (LOPES et al., 1998). Este ixodídeo ocasiona perdas econômicas importantes, em decorrência da queda de produti- 
vidade dos animais e dos gastos com o uso de carrapaticidas (PRATA et al., 1996). É responsável pela transmissão de patógenos aos animais, estando também implicado em saúde pública, destacando-se a transmissão do agente etiológico da febre maculosa, uma das mais freqüentes e conhecidas zoonoses transmitida por carrapatos nas Américas (FONSECA, 1997).

Os conhecimentos de bioecologia da espécie A. cajennense são de fundamental importância no controle de suas populações (LEITE et al., 1997). Estudos realizados em Trinidad por Smith (1975), na Argentina por Guglielmone et al. (1990) e no Brasil por Souza e Serra-Freire (1992), Souza e SerraFreire (1994), Oliveira et al. (2000), Labruna et al. (2002) e Oliveira et al. (2003) caracterizaram a dinâmica populacional de A. cajennense em vida livre e parasitária, demonstrando o desenvolvimento de apenas uma geração por ano, com picos definidos das populações de larvas, ninfas e adultos, e um maior predomínio de estádios imaturos nos meses mais frios e secos e de adultos nos meses mais quentes e chuvosos. Oliveira et al. (2000) e Oliveira et al. (2003) em Pedro Leopoldo, Minas Gerais, Brasil, observaram, em eqüinos e no ambiente, as maiores concentrações de larvas em abril e maio e as de ninfas no mês de julho. Outro fator importante é o tempo de permanência de cada estádio do A. cajennense no hospedeiro. As larvas e ninfas se alimentam por um período de quatro a sete dias, as fêmeas por dez a quatorze dias (OLIVIERI; SERRA-FREIRE, 1984a; OLIVIERI; SERRA-FREIRE, 1984b; PRATA et al., 1996), enquanto que os machos podem sobreviver e permanecerem ativos sexualmente por até 86 dias no hospedeiro (PINTER et al., 2002).

De acordo com Pinheiro (1987) e Bittencourt et al. (1989) a espécie $A$. cajennense exige concentrações mais elevadas de formulações carrapaticidas do que aquelas utilizadas para o controle de Boophilus microplus (Canestrini, 1887). Por uma questão de eficiência e segurança, os produtos do grupo dos piretróides são os únicos indicados para banhos em eqüinos disponíveis no mercado brasileiro (PINHEIRO, 1987; BITTENCOURT et al., 1989; LEITE et al., 1997).

Leite et al. (1997), considerando aspectos epidemiológicos das infestações por $A$. cajennense, elaboraram uma proposta de controle estratégico baseada em módulos de tratamentos carrapaticidas nos eqüinos, banhando os eqüinos a cada sete a dez dias, no período de predominância de larvas e ninfas do carrapato.

Considerando as questões que relacionam $A$. cajennense ao complexo da pecuária e à saúde pública, objetivou-se verificar a eficiência de um programa de controle estratégico de A. cajennense em eqüinos perante situações da prática de campo.

\section{MATERIAL E MÉTODOS}

\section{Local de realização e duração do estudo e condições expe- rimentais}

O experimento foi realizado em uma empresa de pecuária leiteira comercial, com um rebanho bovino de 120 cabeças, localizada no município de Palma, Zona da Mata do estado de Minas Gerais, constituída de 140ha de pastagens nativas e cultivadas e de áreas de preservação permanente com vegetação arbustiva e arbórea. A propriedade apresentava histórico de infestação natural por A. cajennense, porém, não empregava nenhum esquema específico para o controle de carrapatos nos eqüinos. $\mathrm{O}$ estudo, incluindo o período de controle, teve duração de 18 meses, de outubro de 2003 a março de 2005. A fazenda era gerida, hierarquicamente, por um condomínio de proprietários, por um gerente operacional e por três funcionários.

Antes da implantação do programa de controle estratégico, todo o plantel de eqüinos foi avaliado quanto à carga parasitária de estádios adultos. Esta avaliação foi realizada mensalmente compreendendo o período de outubro de 2003 a março de 2004, ano anterior ao programa. As contagens foram realizadas sobre o antímero esquerdo dos animais, multiplicando-se o valor numérico observado por dois, de acordo com Oliveira e Leite (1997). Os dados obtidos nestas análises preliminares serviram como parâmetros para as avaliações comparativas realizadas depois do programa de controle estratégico. Também foram realizadas observações a respeito do gerenciamento da propriedade e da operacionalidade do programa de controle.

\section{Animais e pastagens}

Foram utilizados 16 eqüinos adultos de raça não definida (11 machos e 5 fêmeas). Os animais foram mantidos exclusivamente a pasto, com suplementação mineral. Em abril de 2004, quando do início dos tratamentos carrapaticidas, os eqüinos foram tratados com anti-helmíntico ${ }^{5}$ como parte inicial de um programa compreendido por quatro dosificações anuais. Ao início e no decorrer do estudo todos os eqüinos foram inspecionados quanto aos aspectos clínico-nutricionais, conforme Speirs (1999).

As pastagens eram constituídas por Hyparrhernia rufa (capim jaraguá), Panicum maximum (capim colonião), Brachiaria decumbens (capim braquiária), Brachiaria mutica (capim angola) e Mellinis minutiflora (capim gordura), além de se apresentarem naturalmente infestadas por diversas espécies de plantas invasoras. De acordo com a programação inicial, os eqüinos deveriam permanecer segregados dos bovinos em piquetes préestabelecidos e devidamente limpos (roçados), entretanto, em função do manejo e infra-estrutura da propriedade, estas operações não foram totalmente realizadas.

\section{A estrutura do controle estratégico}

Este programa de controle estratégico de $A$. cajennense foi implantado e avaliado considerando fatores relevantes como: a epidemiologia do parasito, o estabelecimento de módulos de tratamentos, a estrutura de contenção e banho, o treinamento dos operadores, o manejo dos animais e das pastagens e o monitoramento das ações e resultados.

\footnotetext{
${ }^{5}$ Valbazen ${ }^{\circledR 10}$ Cobalto -Pfizer.
} 
Inicialmente, estabeleceu-se um esquema de controle estratégico com base em informações de dinâmica populacional de $A$. cajennense para a região sudeste do Brasil (SOUZA; SERRA-FREIRE, 1992; SOUZA; SERRA-FREIRE, 1994; OLIVEIRA et al., 2000; LABRUNA et al., 2002; OLIVEIRA et al., 2003) e de controle (LEITE et al., 1997), que seria dividido em dois módulos de seis banhos carrapaticidas intervalados por sete dias, previamente planejados da seguinte forma: o primeiro módulo com início na primeira semana do mês de abril de 2004, visando atingir principalmente a fase de predomínio de larvas do carrapato; e o segundo módulo com início na primeira semana de julho de 2004, visando atingir principalmente a fase de maior ocorrência de ninfas; no entanto, por razões técnicas e operacionais, o cronograma foi alterado, estabelecendo-se então oito banhos no primeiro módulo e cinco banhos no segundo. Os animais após serem banhados retornaram ao pasto de origem; além disso, foram banhados sempre que circularam por áreas circunvizinhas, ou seja, fora da propriedade.

A estrutura para contenção dos animais e aplicação dos tratamentos carrapaticidas compunha-se de um tronco de cordoalha de aço com capacidade para cinco eqüinos adultos, uma bomba elétrica, uma caixa d’água de 500 litros, tubulação hidráulica e um aspersor em cada lateral do tronco, possibilitando a operação do sistema por duas pessoas simultaneamente, conforme Leite (2004). Os funcionários da propriedade foram devidamente orientados e treinados para a execução dos banhos carrapaticidas e para o manejo dos animais, e também foram informados da importância do A. cajennense e de seu controle. Utilizou-se um volume por animal de 3 a 5 litros de emulsão carrapaticida, segundo o porte dos animais, tendo como base química um produto piretróide, cipermetrina ${ }^{6}$ na concentração de $0,015 \%$.

De abril a setembro de 2004, a cada 14 dias, os eqüinos e as pastagens foram monitorados quanto às infestações por $A$. cajennense, empregando-se o arraste de flanelas nas pastagens e a raspagem da pelagem dos eqüinos (OLIVEIRA; LEITE, 1997). Como o objetivo do programa de controle foi atingir os estádios imaturos do carrapato, tais observações foram consideradas, tecnicamente, importantes para o estabelecimento dos módulos de tratamentos e da necessidade, ou não, de tratamentos carrapaticidas táticos.

\section{Dados meteorológicos}

Os dados climáticos foram obtidos no Instituto Nacional de Meteorologia (2005) relativos à Estação Meteorológica Santo Antônio de Pádua - RJ, situada a 20 quilômetros de distância do local do estudo, a uma altitude de 95 metros, latitude $21^{\circ} 32^{\prime}$ 'S e longitude $42^{\circ} 09^{\prime} \mathrm{O}$.

\section{Análise estatística dos dados}

Os dados obtidos das contagens dos estádios adulto de $A$. cajennense foram submetidos ao teste não-paramétrico de

\footnotetext{
${ }^{6}$ Ec-Tox CE $15 \%{ }^{\circledR}$ - Schering-Plough Saúde Animal.
}

Mann-Whitney, os valores da razão sexual deste carrapato foram analisados por transformação logarítmica (SAMPAIO, 2002).

\section{RESULTADOS}

Os valores médios das contagens pré e pós-tratamentos carrapaticidas de estádios adultos do $A$. cajennense em eqüinos foram, respectivamente, 78,35 e 43,21 carrapatos por animal, (Tabela 1). Demonstrando uma redução significativa da carga parasitária $(\mathrm{P}<0,03)$ de $44,85 \%$ para o período de outubro de 2004 a março de 2005 em relação ao mesmo período do ano anterior.

Pode-se observar pela Figura 1, que os maiores picos de adultos de $A$. cajennense ocorreram nos meses de fevereiro e março tanto no período pré-tratamentos como no período póstratamentos. Quando se analisou este bimestre, separadamente, observou-se que houve redução estatisticamente significativa $(\mathrm{P}<0,0001)$ de $59,74 \%$, ou seja, de 135,06 para 54,37 adultos de $A$. cajennense por eqüino (Tabela 2). Entretanto, comparando-se as contagens referentes ao mês de novembro,

Tabela 1. Valores médios e desvios-padrão das contagens de adultos de Amblyomma cajennense em eqüinos antes e após o programa de controle estratégico, respectivamente, nos períodos de outubro de 2003 a março de 2004 e outubro de 2004 a março de 2005 - Palma/MG

\begin{tabular}{lccc}
\hline \multirow{2}{*}{ Meses } & \multicolumn{3}{c}{ A. cajennense } \\
\cline { 2 - 4 } & Pré-tratamentos & Pós-tratamentos & $\begin{array}{c}\text { Percentual de } \\
\text { variação \% }\end{array}$ \\
\hline Outubro & $20,67( \pm 12,63)^{\mathrm{a}}$ & $26,67( \pm 11,91)^{\mathrm{a}}$ & $+29,03$ \\
Novembro & $14,18( \pm 14,22)^{\mathrm{a}}$ & $38,5( \pm 18,91)^{\mathrm{b}}$ & $+171,51$ \\
Dezembro & $34,36( \pm 38,81)^{\mathrm{a}}$ & $43,50( \pm 22,55)^{\mathrm{a}}$ & $+26,6$ \\
Janeiro & $56,93( \pm 41,09)^{\mathrm{a}}$ & $30,75( \pm 14,71)^{\mathrm{b}}$ & $-45,99$ \\
Fevereiro & $149,12( \pm 87,57)^{\mathrm{a}}$ & $44,50( \pm 22,39)^{\mathrm{b}}$ & $-70,16$ \\
Março & $121,00( \pm 63,99)^{\mathrm{a}}$ & $65,24( \pm 28,77)^{\mathrm{b}}$ & $-46,08$ \\
Média global & $78,35( \pm 76,64)^{\mathrm{a}}$ & $43,21( \pm 24,17)^{\mathrm{b}}$ & $-44,85$ \\
\hline
\end{tabular}

*Letras minúsculas na mesma linha, não coincidentes, diferem estatisticamente pelo teste de Mann-Whitney ao nível de 5\% de significância.

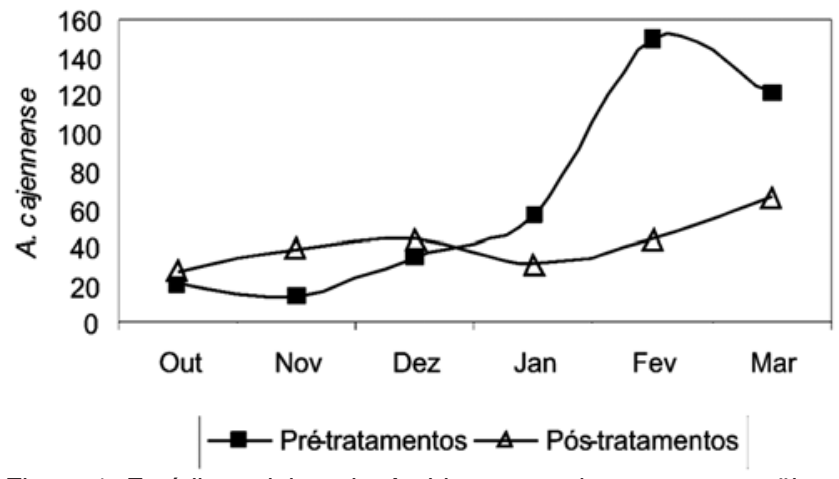

Figura 1. Estádios adultos do Amblyomma cajennense em eqüinos antes e após o programa de controle estratégico, respectivamente, nos períodos de outubro de 2003 a março de 2004 e outubro de 2004 a março de 2005 - Palma/MG 
observou-se um aumento significativo $(\mathrm{P}<0,05)$ da carga parasitária de adultos de $A$. cajennense nos eqüinos (Tabela 1 e Figura 1).

As contagens específicas de machos e de fêmeas de $A$. cajennense nos eqüinos estão representadas nas Figuras 2 e 3. Em geral, ocorreu uma redução de $36,28 \%(P<0,05)$ e de 56,59\% $(\mathrm{P}<0,004)$ das cargas parasitárias de machos e fême-

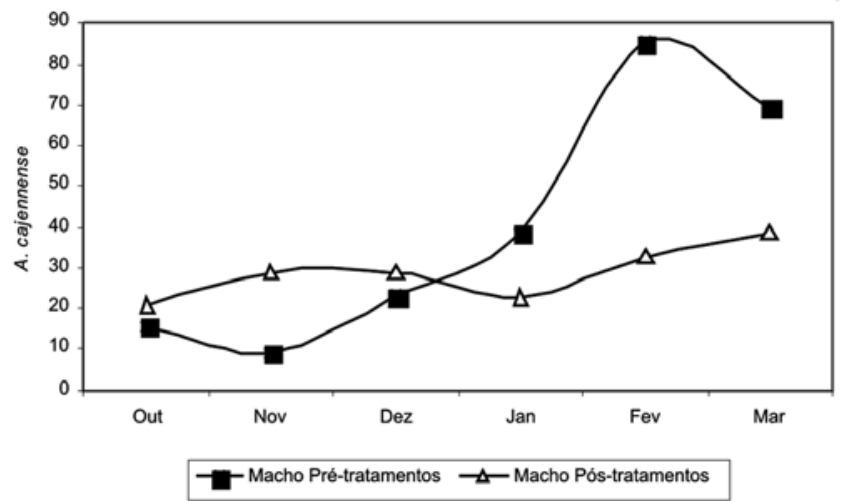

Figura 2. Machos de Amblyomma cajennense em eqüinos antes e após o programa de controle estratégico, respectivamente, nos períodos de outubro de 2003 a março de 2004 e outubro de 2004 a março de 2005 - Palma/MG.

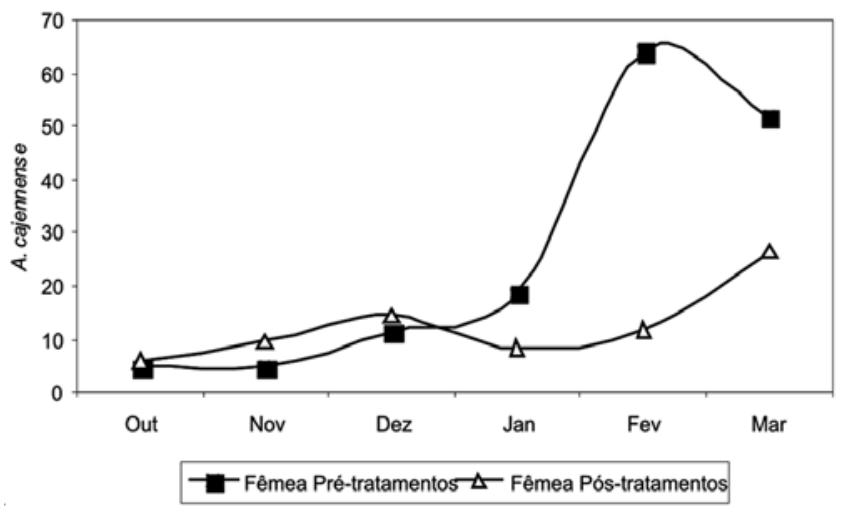

Figura 3. Fêmeas de Amblyomma cajennense em eqüinos antes e após o programa de controle estratégico, respectivamente, nos períodos de outubro de 2003 a março de 2004 e outubro de 2004 a março de 2005 - Palma/MG.

Tabela 2. Valores médios e desvios-padrão das contagens de adultos de Amblyomma cajennense em eqüinos antes e após o programa de controle estratégico, nos meses de fevereiro e março de 2004 e 2005 - Palma/MG

\begin{tabular}{cccc}
\hline A. cajennense & $\begin{array}{c}\text { Fevereiro/março } \\
(\text { AC) } 2004\end{array}$ & $\begin{array}{c}\text { Fevereiro/março } \\
(\text { PC)2005 }\end{array}$ & $\begin{array}{c}\text { Percentual de } \\
\text { variação \% }\end{array}$ \\
\hline Machos & $77,19( \pm 47,44)^{\mathrm{a}}$ & $33,75( \pm 16,68)^{\mathrm{b}}$ & $-56,27$ \\
Fêmeas & $57,87( \pm 31,78)^{\mathrm{a}}$ & $20,62( \pm 12,64)^{\mathrm{b}}$ & $-64,37$ \\
Média global & $135,06( \pm 78,59)^{\mathrm{a}}$ & $54,37( \pm 28,04)^{\mathrm{b}}$ & $-59,74$ \\
\hline
\end{tabular}

*Letras minúsculas na mesma linha, não coincidentes, diferem estatisticamente pelo teste de Mann-Whitney ao nível de 0,001\% de significância.

$\mathrm{AC}=$ Antes do controle estratégico.

$\mathrm{PC}=$ Depois do controle estratégico. as, respectivamente. No entanto, comparando-se os períodos referentes a fevereiro/março constatou-se diferença extremamente significativa ( $\mathrm{P}<0,0001)$, com decréscimo de $56,28 \%$ de machos e 64,38\% de fêmeas de $A$. cajennense nos eqüinos após o programa de controle (Tabela 2).

Através dos percentuais de razão sexual de $A$. cajennense, verificou-se um aumento $(\mathrm{P}<0,05)$ do número de machos em relação ao de fêmeas em todos os meses de contagens póstratamentos, a exceção do mês de novembro em que tal variação não foi significativa (Figura 4). Foram observadas as maiores proporções de machos por fêmea em outubro, com 3,51 machos para cada fêmea no período pré-tratamentos e 4,07 machos para cada fêmea no período pós-tratamentos. As menores proporções de machos por fêmea foram observadas no mês de março com 1,36 e 1,59 machos para cada fêmea para as contagens pré e pós-tratamentos, respectivamente. Os machos de A. cajennense foram predominantes em todas as contagens, pré e pós-tratamentos. As fêmeas representaram 40,07\% da população total de adultos de A. cajennense no período pré-tratamentos, percentual reduzido significativamente $(\mathrm{P}<0,05)$ para $31,31 \%$ no período pós-tratamentos.

Na Tabela 3 estão representadas as observações do monitoramento quinzenal da população de A. cajennense em vida livre e parasitária, através do arraste de flanela nas pastagens e da raspagem dos eqüinos, no período de abril a setembro de 2004.

As observações sobre a operacionalidade do controle estratégico estão representadas no Quadro 1.

No decorrer do estudo, perante as análises semiológicas, não foi observada nenhuma reação adversa nos eqüinos. A metodologia empregada para os banhos carrapaticidas foi eficiente para a contenção dos animais e aplicação da emulsão carrapaticida. A operação de banho teve uma duração média de 35 segundos por animal, quando executada por dois operadores. O custo com o produto carrapaticida foi R $\$ 0,19$ ou US\$ 0,076 por tratamento por animal. A estrutura para contenção e banho dos animais custou R $\$ 1200,00$ ou US $\$ 480,00$, valores indexados no período de execução do programa de controle.

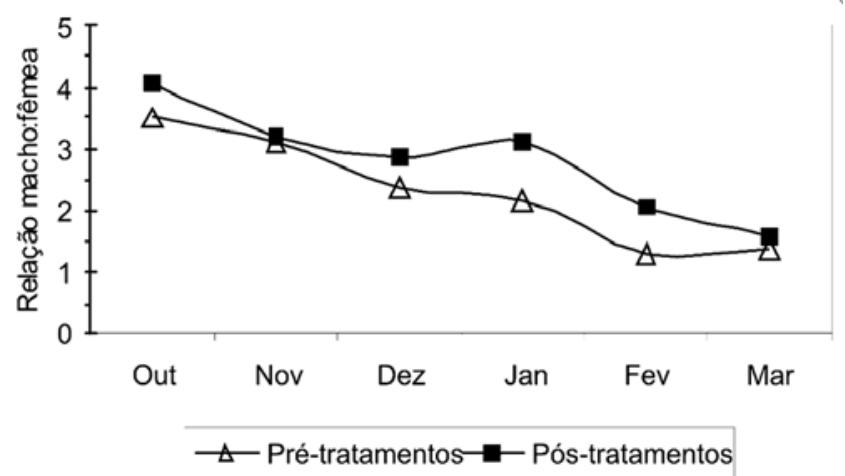

Figura 4. Razão sexual de Amblyomma cajennense, em eqüinos antes e após o programa de controle estratégico, respectivamente, nos períodos de outubro de 2003 a março de 2004 e outubro de 2004 a março de 2005 - Palma/MG. 
Tabela 3. Monitoramento da população de Amblyomma cajennense nas pastagens e nos animais, realizado a cada quatorze dias, no período de abril a setembro de 2004, Palma/MG

\begin{tabular}{|c|c|c|c|c|c|c|c|c|c|c|c|c|}
\hline \multirow[t]{3}{*}{ Estádios } & \multicolumn{12}{|c|}{ Monitoramento de $A$. cajennense nas pastagens e nos eqüinos } \\
\hline & \multicolumn{2}{|c|}{ Abril } & \multicolumn{2}{|c|}{ Maio } & \multicolumn{2}{|c|}{ Junho } & \multicolumn{2}{|c|}{ Julho } & \multicolumn{2}{|c|}{ Agosto } & \multicolumn{2}{|c|}{ Setembro } \\
\hline & AV1 & AV2 & AV1 & AV2 & $\overline{\mathrm{AV} 1}$ & AV2 & $\overline{A V 1}$ & AV2 & AV1 & AV2 & $\overline{A V 1}$ & AV2 \\
\hline \multicolumn{13}{|l|}{ Pastagens } \\
\hline Larvas & - & - & + & + & + & + & + & - & - & + & + & + \\
\hline Ninfas & - & - & - & - & - & - & + & - & + & + & + & + \\
\hline Adultos & - & - & - & - & - & - & - & - & - & - & - & - \\
\hline \multicolumn{13}{|l|}{ Eqüinos } \\
\hline Larvas & + & - & - & + & - & - & + & - & - & - & + & + \\
\hline Ninfas & - & - & - & - & - & - & + & - & - & + & + & + \\
\hline Adultos & + & + & + & + & + & + & + & + & + & + & + & + \\
\hline
\end{tabular}

*AV1 = $1^{\mathrm{a}}$ avaliação do mês; AV2 = 2 ${ }^{\mathrm{a}}$ avaliação do mês; - = Ausência; + = Presença.

** O monitoramento nas pastagens foi realizado através do arraste de flanela e nos eqüinos através de raspagem.

Quadro 1. Fatores operacionais de uma proposta de controle estratégico de Amblyomma cajennense em eqüinos perante circunstâncias de campo de um sistema de pecuária - Pal$\mathrm{ma} / \mathrm{MG}, 2004$

\begin{tabular}{lc}
\hline \multicolumn{1}{c}{ Planejamento técnico } & $\begin{array}{c}\text { Grau de } \\
\text { execução }\end{array}$ \\
\hline Cronograma fixo de banhos carrapaticidas & Parcial \\
Estrutura para contenções dos animais & Total \\
Operações de banho & Total \\
Pastos separados para eqüinos & Não realizado \\
Limpeza dos pastos & Parcial \\
Retorno dos eqüinos ao pasto de origem após & Total \\
os banhos & \\
Banho dos eqüinos quando circularam por áreas & Total \\
externas à propriedade & \\
Manejo sanitário dos eqüinos & Total \\
Escrituração dos acontecimentos & Não realizado \\
\hline
\end{tabular}

\section{DISCUSSÃO}

As informações obtidas no presente estudo consolidam a validade dos princípios epidemiológicos preconizados por Leite et al. (1997) para o controle do A. cajennense em eqüinos, e ainda, esclarecem alguns pontos críticos importantes para a implantação e execução deste tipo de proposta tecnológica, os quais são determinados pelas estruturas de gerenciamento e operacionadade do sistema. Com todo o connecimento já acumulado sobre biologia e epidemiologia de A. cajennense, ainda são necessários mais estudos a respeito da aplicabilidade prática de tais informações em situações de campo. Lopes (2000) e Labruna et al. (2004) avaliaram a proposta de Leite et al. (1997), embora os estudos tenham sido realizados em eqüinos a pasto, foram mantidas condições experimentais controladas, sem considerar importantes variáveis relacionadas ao sistema produtivo, tais como: o modelo de gestão da empresa rural, a atividade econômica e a operacionalidade do programa.

Foram observadas as maiores populações de adultos de $A$. cajennense parasitando os eqüinos nos meses de fevereiro e março nas contagens pré e pós-tratamentos, este foi também o período de maior percentual de redução da carga parasitária após os tratamentos carrapaticidas (59,74\%) (Tabela 2). Labruna et al. (2004) em Pirassununga, São Paulo, Brasil, empregaram um programa de controle deste carrapato em eqüinos, avaliando contagens nos meses de janeiro e fevereiro a cada 21 dias, antes e após os tratamentos carrapaticidas, obtiveram uma redução 58,6\% carga parasitária de adultos quando banharam os eqüinos com uma formulação piretróide da primeira semana de abril à última de julho, e 89,7\% quando banharam os animais da primeira semana de abril à última de outubro, em ambas as situações os animais foram banhados a cada sete dias, com alfametrina na concentração de 0,01\%. Pode-se defrontar parcialmente o presente estudo com o experimento realizado por Labruna et al. (2004) com base nos objetivos propostos por ambos; no entanto, devem-se ressalvar particularidades metodológicas e circunstanciais importantes. Além das diferenças no período e quantidade de banhos, período e freqüência das avaliações, aqueles autores utilizaram pastagens exclusivas e permanentes para os eqüinos e taxa de lotação fixa.

Lopes (2000), em Pedro Leopoldo, Minas Gerais, Brasil, aplicou seis tratamentos carrapaticidas em eqüinos intervalados por 10 dias, nos meses de maio e junho e outros seis tratamentos nos meses de agosto e setembro, e realizou
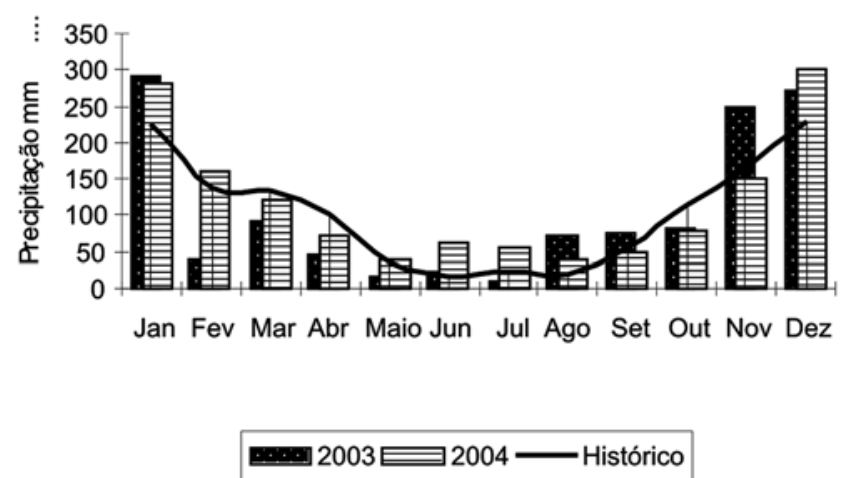

Figura 5. Precipitação mensal (mm) no período de janeiro de 2003 a dezembro de 2004 e normal climatológica de precipitação (19611990) na Estação Meteorológica de Santo Antônio de Pádua, RJ, segundo o Instituto Nacional de Meteorologia (2005). 
contagens dos estágios imaturos de $A$. cajennense nos eqüinos respeitando o mesmo cronograma estabelecido para os tratamentos carrapaticidas, onde verificou uma redução de 66,67\% de larvas e de $100 \%$ de ninfas. Os períodos de vida parasitária de larvas e de ninfas de A. cajennense devem ser considerados em esquemas de controle direcionados aos hospedeiros, visando o contato do carrapaticida com uma maior percentagem de estágios imaturos de populações deste carrapato.

No presente estudo verificou-se uma maior concentração de machos em relação a fêmeas de A. cajennense em vida parasitária; além disso, a proporção macho:fêmea foi significativamente maior em outubro perante os outros meses de contagens, dinâmica semelhante à relatada por Oliveira et al. (2003) e Labruna et al. (2004). Os machos de A. cajennense aparecem mais cedo e em maior densidade populacional nas pastagens e nos animais, do que as fêmeas (LABRUNA et al., 2002). Segundo Sonenshine (1991) a infestação expressiva de machos antes das fêmeas, pode estar relacionada à necessidade de que os machos parasitem e se alimentem primeiramente, atinjam a maturidade sexual e produzam feromônios para atrair fêmeas, ninfas e outros machos a se fixarem no hospedeiro. Entretanto, Pinter et al. (2002) e Freitas et al. (1999), em condições laboratoriais, a partir de ninfas ingurgitadas coletadas de eqüinos obtiveram $35-36 \%$ de machos e $64-65 \%$ de fêmeas de $A$. cajennense, respectivamente. As diferentes proporções sexuais de $A$. cajennense observadas entre contagens realizadas em hospedeiros a campo e em condições de laboratório, podem estar relacionadas ao maior tempo de parasitismo dos machos, pois dependendo do intervalo de contagens, pode-se contabilizar o mesmo macho parasitando o mesmo hospedeiro em mais de uma ocasião (LABRUNA et al., 2002; PINTER et al., 2002).

Na Tabela 1 e nas Figuras 1, 2 e 3, verifica-se que apesar da população total de adultos de $A$. cajennense ter diminuído significativamente após os tratamentos carrapaticidas, ocorreu um aumento considerável $(\mathrm{P}<0,05)$ de carrapatos adultos no mês de novembro de 2004 em relação ao mesmo período do ano anterior. Tais variações podem advir de interferências no programa de controle de A. cajennense, no manejo dos animais e do ambiente, além de influências climáticas na região e/ou ocorrências de anomalias climatológicas entre os dois períodos observados. De acordo com o Instituto Nacional de Meteorologia (2005) houve anomalias climatológicas importantes no período de janeiro de 2003 a dezembro de 2004, principalmente com relação aos gradientes de precipitação, com expressivos aumentos nos volumes de chuvas em alguns meses do ano de 2004 em relação à média histórica (Figura 5). Segundo Leite et al. (1997), o meio ambiente físico e climático regula em grande parte a dinâmica das populações de parasitos. Paula et al. (2004) ao imergirem larvas não alimentadas de $A$. cajennense em água destilada verificaram alterações significativas no tempo de longevidade das mesmas, com efeitos deletérios a partir 48h de imersão. Labruna et al. (2002) demonstraram haver correlação negativa entre o número de larvas e ninfas de $A$. cajennense ingurgitadas com os valores de temperatura, dias de chuva, fotoperíodo e umidade relativa do ar; já para os estádios adultos os autores verificaram correlação positiva com os valores de temperatura, umidade relativa do ar, total de chuvas, dias de chuva e fotoperíodo.

No mês de maio de 2004, sete dias após o último banho programado para o primeiro módulo, verificou-se ainda, a presença de larvas nas pastagens e nos animais (Tabela 3), o que determinou a necessidade de realizar dois tratamentos carrapaticidas táticos, quando então, percebeu-se a ausência de estádios imaturos do carrapato nos animais e o módulo foi encerrado.

O segundo módulo de banhos teve início na primeira semana de julho, momento em que já se verificava o reaparecimento de estádios imaturos de A. cajennense nos animais. O último banho deste módulo não foi realizado, pois na semana na qual estava previsto, choveu por vários dias consecutivos, inviabilizando a operação. Apesar de ter sido verificada a presença de larvas e ninfas nas pastagens e nos animais nos meses de agosto e setembro, não foi possível realizar banhos carrapaticidas táticos, uma vez que, em decorrência dos altos índices pluviométricos determinando condições propícias ao plantio, os operadores do sistema de controle do carrapato foram redirecionados para funções relacionadas à implantação de pastagens, o que era a "prioridade" da empresa naquele momento.

No período de monitoramento (abril a setembro de 2004), através do arraste de flanela, não foram encontrados estádios adultos de A. cajennense nas pastagens. Ainda durante o período de abril a setembro de 2004 foram observadas baixas cargas parasitárias de adultos nos eqüinos, sempre inferiores a dez carrapatos por animal. Segundo Labruna et al. (2002) e Oliveira et al. (2003), adultos de A. cajennense ocorrem em vida livre e parasitária durante todo o ano. As informações epidemiológicas sobre o A. cajennense, os hospedeiros e o ambiente são importantes para a tomada de decisões técnicas, podendo indicar o momento mais adequado para se dar início, interromper ou encerrar a seqüência de banhos.

Embora os índices de redução da carga parasitária de $A$. cajennense tenham sido significativos, as contagens realizadas após os tratamentos carrapaticidas ainda revelaram um considerável parasitismo por adultos de A. cajennense, com uma média de 43,21 carrapatos adultos por animal no período de outubro de 2004 a março de 2005, e de 54,37 em fevereiro e março de 2005. Por questões operacionais de falta de mão-de-obra e de recursos para investimento na estrutura de separação e limpeza dos pastos, não foi possível separar os eqüinos dos bovinos e mantê-los em pastos específicos e limpos de plantas invasoras a contento do planejamento inicial e dos fundamentos teóricos propostos por Leite et al. (1997), permanecendo as condições ambientais e climáticas para desenvolvimento do A. cajennense e de hospedeiros alternativos. Circunstâncias estas que, certamente interferiram nos aspectos técnicos de execução do programa e que 
possivelmente influenciaram nos resultados finais. No Quadro 1 estão representados alguns aspectos técnicos da proposta de controle, bem como seus respectivos níveis de exeqüibilidade para o sistema de produção em que foram aplicados.

No controle de A. cajennense em uma propriedade, as áreas circunvizinhas são de extrema importância, pois, segundo Lopes et al. (1998), este carrapato por ser trioxeno e de baixa especificidade parasitária tem um grande poder de dispersão por extensas áreas. A presença de mamíferos e pássaros silvestres contribui para a manutenção e dispersão de $A$. cajennense (LOPES et al., 1998; ROJAS et al., 1999). Além disso, os bovinos de exploração leiteira são facilmente parasitados por A. cajennense (FALCE, 1986; SERRAFREIRE; CUNHA, 1987).

Torna-se importante destacar que o ciclo de vida de $A$. cajennense pode durar até 3,5 anos, portanto, para garantir o êxito de um programa, as operações de controle devem perdurar pelo mesmo período de tempo ou mais, sabendo que as larvas deste carrapato podem permanecer em jejum no ambiente por até seis meses, as ninfas por até um ano e os adultos por até dois anos (LEITE et al., 1997). Sendo assim, esperam-se reduções da população do carrapato, de geração a geração, podendo reduzir gradativamente o número de banhos. Labruna et al. (2004) verificaram uma redução significativa de A. cajennense nos eqüinos após o primeiro ano de controle; no entanto, no ano seguinte, quando os eqüinos não foram banhados, a população de carrapatos voltou a crescer, reforçando a necessidade de continuidade nas ações de controle. Leite et al. (1997) indicam também, para a primavera e verão, período de predomínio de estádios adultos, a retirada manual de fêmeas ingurgitadas do carrapato. Esta prática, no entanto, não foi realizada para não interferir na avaliação dos tratamentos carrapaticidas.

O programa de controle estratégico, utilizando uma emulsão carrapaticida na concentração recomendada para o controle de B. microplus em bovinos, apresentou efeitos sobre os estádios larval e ninfal do $A$. cajennense, conseqüentemente reduzindo a carga parasitária de estádios adultos do carrapato; o que corrobora com as informações de Pinheiro (1987) e Bittencourt et al. (1989) que demonstraram que as larvas e ninfas deste carrapato são mais sensíveis que os estádios adultos, enquanto que estes são 1,8 vezes mais resistentes que os estádios adultos de B. microplus. Fato que aliado à possibilidade de se estabelecer o número de banhos de acordo com o nível de infestação da propriedade, resulta em uma racionalização do uso do produto carrapaticida e da mão-deobra envolvida, determinando menores riscos de contaminação para os animais, para o homem e para o meio ambiente. Outra observação a ser ponderada é que, no decorrer do estudo com as freqüentes manipulações, os eqüinos tornaram-se mais dóceis e condicionados ao manejo do programa de controle contra A. cajennense e também perante as atividades de rotina da propriedade. O sistema empregado para a contenção dos animais e aplicação dos tratamentos carrapaticidas foi seguro para os animais e para os operadores, possibilitando fácil acesso às diferentes regiões do corpo dos eqüinos e resultando em agilidade e qualidade na execução dos banhos, podendo inclusive ser utilizado para o controle de carrapatos em bovinos. Segundo Leite (2004), o uso de equipamentos inadequados constitui uma das principais causas de erros na aplicação de carrapaticidas.

Além dos resultados específicos referentes ao controle do carrapato, o presente estudo aborda diferentes questões de gerenciamento e operacionalidade do sistema de produção envolvido, fornecendo informações a serem consideradas no planejamento e implantação de programas de controle que visem à eficiência da aplicação dos conhecimentos técnicos e científicos, coerentemente com a atividade econômica, com as práticas de manejo e com os princípios bioéticos. De forma a constituir alternativas viáveis para o desenvolvimento do setor pecuário em equilíbrio com a sanidade animal e com a saúde pública.

Agradecimentos: Este trabalho teve o apoio logístico e operacional da fazenda Rancho Agropecuária e sua equipe.

\section{REFERÊNCIAS BIBLIOGRÁFICAS}

ARAGÃO, H.B. Ixodidas brasileiros e de alguns países limítrofes. Memórias do Instituto Oswaldo Cruz, v.31, n.4, p.759-843, 1936.

BITTENCOURT, V.R.E.; MASSARD, C.L.; GRISI, L. Atividade in vitro de alguns piretróides sintéticos no carrapato Amblyomma cajennense (Fabricius, 1787). Pesquisa Agropecuária Brasileira, v.24, n.10, p.1193-1199, 1989.

FALCE, H. C. Infestações múltiplas por ixodídeos (Acari: Ixodidae) em bovinos e eqüídeos no primeiro planalto do Estado do Paraná. Revista do Setor de Ciências Agrárias, v.5, n.1-2, p.11-13, 1986.

FONSECA, A.H. Doenças transmitidas ao homem e animais por carrapatos que parasitam eqüinos. In: SIMPÓSIO SOBRE CONTROLE DE PARASITOS, 2., 1997, Colina. Anais... Campinas: CGE, 1997. p.1-8.

FREITAS, C.M.V.; LEITE, R.C.; OLIVEIRA, P.R.; BICALHO, K.A.; LISBOA, E.CM. Comparação entre alguns parâmetros biológicos de ninfas ingurgitadas e adultos não alimentados de Amblyomma cajennense (Fabricius, 1787) (Acari: Ixodidae).In: SEMINÁRIO DE PARASITOLOGIA VETERINÁRIA DOS PAÍSES DO MERCOSUL, 2., 1999, Salvador. Anais... Salvador: CBPV, 1999. p.83.

GUGLIELMONE, A.A.; MANGOLD, A.J.; AGUIRRE, D.; GAIDO, A.B. Ecological aspects of ticks found on cattle in Salta, Northwestern Argentina. Veterinary Parasitology, v.35, n.1-2, p.93-101, 1990.

INSTITUTO NACIONAL DE METEOROLOGIA. 2005. Disponível em: <http://www.inmet.gov.br/ html/clima. > . Acesso em: 12 dez 2005.

LABRUNA, M.B.; KASAI, N.; FERREIRA, F.; FACCINI, 
J.L.H.; GENNARI, S.M. Seasonal dynamics of ticks (Acari: Ixodidae) on horses in the state of São Paulo, Brazil. Veterinary Parasitology, v.105, n.1, p.65-77, 2002.

LABRUNA, M.B; LEITE, R.C.; GOBESSO, A.A.O.; GENNARI, S.M.; KASAI, N. Controle estratégico do carrapato Amblyomma cajennense em eqüinos. Ciência $R u-$ ral, v.34, n.1, p.195-200, 2004.

LEITE, R.C.; OLIVEIRA, P.R.; LOPES, C.M.L.; FREITAS, C.M.V. Alguns aspectos epidemiológicos das infestações por Amblyomma cajennense: uma proposta de controle estratégico. In: SIMPÓSIO SOBRE CONTROLE DE PARASITOS, 2., 1997, Colina. Anais... Campinas: CGE, 1997. p.9-14.

LEITE, R.C. Práticas auxiliares no manejo parasitário em bovinos. Merial - Coleção Gado de Corte, n.8, p.1-15, 2004.

LOPES, C.M.L.; LEITE, R.C.; LABRUNA, M.B.; OLIVEIRA, P.R.; BORGES, L.M.F.; RODRIGUES, Z.B.; CARVALHO, H.A.; FREITAS, C.M.V.; VIEIRA Jr., C.R. Host specificity of Amblyomma cajennense (Fabricius, 1787) (Acari: Ixodidae) with comments on the drop-off rhythm. Memórias do Instituto Oswaldo Cruz, v. 93, n.3, p.347351, 1998.

LOPES, C.M.L. Amblyomma cajennense (Fabricius, 1787) (Acari: Ixodidae): aspectos biológicos e comportamentais da perspectiva do controle estratégico. 2000. 60f. Tese (Doutorado em Ciência Animal) - Escola de Veterinária da Universidade Federal de Minas Gerais, Belo Horizonte, 2000.

OLIVER Jr., J.H. Biology and systematics of ticks (Acari: Ixodidae). Annual Review of Ecology and Systematics, v.20, n.1, p.397-430, 1989.

OLIVEIRA, P.R.; LEITE, R.C. Metodologia para estudos epidemiológicos em carrapatos de eqüinos. In: SIMPÓSIO SOBRE CONTROLE DE PARASITOS, 2., 1997, Colina. Anais... Campinas: CGE, 1997. p.21-24.

OLIVEIRA P.R.; BORGES, L.M.F.; LOPES, C.M.L.; LEITE, R.C. Population dynamics of the free-living stages of Amblyomma cajennense (Fabricius, 1987) (Acari: Ixodidae) on pastures of Pedro Leopoldo, Minas Gerais State, Brazil. Veterinary Parasitology, v.92, n.4, p.295301, 2000.

OLIVEIRA, P.R.; BORGES, L.M.F.; LEITE, R.C.; FREITAS, C.MV. Seasonal dynamics of the Cayenne tick. Amblyomma cajennense on horses in Brazil. Medical and Veterinary Entomology, v.17, n.4, p.412-416, 2003.

OLIVIERI, J.A.; SERRA-FREIRE, N.M.S. Estádio larval do ciclo biológico de Amblyomma cajennense. Arquivos da Universidade Federal Rural do Rio de Janeiro, v.7, n.2, p.139-147, 1984a.

OLIVIERI, J.A.; SERRA-FREIRE, N.M.S. Estádio ninfal do ciclo biológico de Amblyomma cajennense. Arquivos da
Universidade Federal Rural do Rio de Janeiro, v.7, n.2, p.149-148, 1984b.

PAULA, A.R.; PIRANDA, E.M.; FACCINI, J.L.H.; DAEMON, E. Efeito da imersão de larvas não alimentadas de Anocentor nitens (Neumann, 1897) e Amblyomma cajennense (Fabricius, 1787) (Acari: Ixodidae) em água destilada. Revista Brasileira de Parasitologia Veterinária, v.13, n.1, p.13-17, 2004.

PINHEIRO, V.R.E. Avaliação do efeito carrapaticida de alguns piretróides sintéticos sobre o carrapato Amblyomma cajennense (Fabricius, 1787) (Acarina: Ixodidae). Hora Veterinária, v.7, n.40, p.21-25, 1987.

PINTER, A.; LABRUNA, M.B; FACCINI, J.L.H. The sex ratio of Amblyomma cajennense (Acari: Ixodidae) with notes on the male feeding period in the laboratory. Veterinary Parasitology, v.105, n.1, p.79-88, 2002.

PRATA, M.C.A.; ALONSO, L.S.; SANAVRIA, A. Parâmetros biológicos do estádio ninfal de Amblyomma cajennense (Fabricius, 1787) (Acari: Ixodidae) em coelhos. Revista Brasileira de Ciência Veterinária, v.3, n. 2, p.55-57, 1996.

ROHR, C. J. Estudos sobre Ixodidas do Brasil. Rio de Janeiro: Instituto Oswaldo Cruz, 1909. 200 p.

ROJAS, R.; MARINI, M.A.; COUTINHO, A.T. Wild birds hosts of A. cajennense (Fabricius, 1787) (Acari: Ixodidae). Memórias do Instituto Oswaldo Cruz, v.94, n.1, p.315-322, 1999.

SAMPAIO, I.B.M. Estatística aplicada à experimentação animal. Belo Horizonte: Fundação de Estudo e Pesquisa em Medicina Veterinária e Zootecnia, 2002. 265p.

SERRA-FREIRE, N.M.; CUNHA, D.W. Amblyomma cajennense: comportamento de ninfas e adultos como parasitos de bovinos. Revista Brasileira de Parasitologia Veterinária, v.9, n.5, p.100-103, 1987.

SMITH, M.W. Some aspects of the ecology and lifecycle of Amblyomma cajennense (Fabricius, 1787) in Trinidad and their influence on tick control measures. Annals of Tropical Medicine and Parasitology, v.69, n.1, p.121-129, 1975.

SONENSHINE, D.E. Tick pheromones. In: SONENSHINE, D.E. Biology of ticks. New York: Oxford University. 1991. v.1, cap. 19, p.331-369.

SOUZA, A.P.; SERRA-FREIRE, N.M. Variação sazonal dos estádios adultos de Amblyomma cajennense e Anocentor nitens, como parasitas de cavalos no município de Itaguaí, RJ, Brasil. Revista Brasileira de Parasitologia Veterinária, v.1, n.1, p.31-34, 1992.

SOUZA, A.P.; SERRA-FREIRE, N.M. Variação sazonal da fase não parasitária de Amblyomma cajennense e Anocentor nitens no município de Itaguaí, RJ: Avaliação epidemiológica e metodológica. Revista da Universidade Rural: Série Ciências da vida, v.16, n.1-2, p.67-74, 1994.

SPEIRS, V.C. Exame clínico de eqüinos. Porto Alegre: Artmed, 1999. 366p.

Recebido em 21 de maio de 2007.

Aceito para publicação em 17 de outubro de 2007. 